\title{
ERGENLER ILE ANNE-BABALARININ EMPATIK BECERILERININ INCELENMESI
}

\section{A STUDY ON EMPATHY SKILLS OF ADOLESCENTS AND THEIR PARENTS}

\author{
Dr. A. Deniz HASDEMIR ${ }^{1}$
}

Prof.Dr. Aysel KÖKSAL AKYOL ${ }^{2}$

\begin{abstract}
ÖZET
$\mathrm{Bu}$ araştırmada, ergenler ile anne-babalarının empatik becerilerinin incelenmesi ve ergenin cinsiyetinin ergenlerin ve anne-babalarının empatik becerileri üzerinde farklılığa neden olup olmadığının belirlenmesi amaçlanmıştır. Araştırmanın çalışma grubunu, Ankara il merkezinde bulunan lise ikinci sınıfta öğrenimine devam eden 300 ergen ve anne-babaları (300 anne, 300 baba) olmak üzere toplam 900 kişi oluşturmuştur. Araştırmada veri toplama aracı olarak Demografik Bilgi Formu ile Dökmen tarafından geliştirilen Empatik Beceri Ölçeği B Formu (EBÖ-B Formu) kullanılmıştır. Verilerin analizinde; iki faktörlü varyans analizi (ANOVA) ve Tukey testi uygulanmıştır. Araştırma sonucunda, ergenin, anne ve babanın empatik becerileri arasında anlamlı bir farklılığın olduğu $(p<01)$, ergenin cinsiyetinin ergenlerin, anne ve babaların empatik becerilerinde anlamlı bir farklılığa neden olmadığı saptanmıştır ( $p>05)$.
\end{abstract}

Anahtar Sözcük: Empati, ergen, anne, baba

\section{ABSTRACT}

In this study, examination of adolescents and their parents' empathic skills and adolescent gender differences on the variables of adolescents and their parents' empathic skills to determine whether there is cause. The study group, who continued his education in the second year high school located in the city center of Ankara, 300 adolescents and their parents (300 mothers, 300 fathers) has established a total of 900 people. Data collection tools used in the study included a Demographic Information Form and Empathic Ability Scale-Form B developed by Dökmen. Analysis of the data, two-factor

\footnotetext{
${ }^{1}$ Deniz Kreş ve Gündüz Bakımevi, e-posta: denizyuva@gmail.com

2 Ankara Üniversitesi Sağlık Bilimleri Fakültesi Çocuk Gelişimi Bölümü, e-posta: koksalaysel@gmail.com.
} 
analysis of variance (ANOVA) and Tukey's test was used. As a result, the empathic skills of the adolescent, mother and father was significant difference between empathic skills $(p<01)$, gender of adolescents does not cause a significant difference on the empathic skill of adolescents, mothers and fathers $(p>.05)$.

Key Words: Empathy, adolescent, mother, father

\section{GíRiş}

Diğer insanlar tarafından anlaşılmak ve önem verilmek bireyi rahatlatmakta ve kendisini iyi hissetmesine neden olmaktadır. Empatik beceri, iletişim çatışmalarını engellemekte ve daha olumlu ilişkilerin kurulmasını sağlamaktadır. Böylece, kişiler arasında iyi ilişkiler kurulmakta, hatta kişilerarası ilişkilerde empatik beceriyi kullanan bir bireyin zamanla karşısındaki kişiye model olarak empatik iletişimin yaygınlaşması söz konusu olmaktadır (Dökmen, 1994; Kalliopuska, 1992; Köksal, 2000a; Yüksel, 2004; Woolfolk, 1993)

Sosyal bir varlık olan insan, yaşamının her döneminde diğer bireylerle ilişki içerisindedir. İnsanın başkalarıyla ilişki kurması temel gereksinimlerden birisidir ve bu ilişkilerinde başarılı olabilmesi kendisini ve başkalarını anlayabilmesine ve kabul etmesine bağlıdır. Diğer insanlarla kurulan ilişkiler, bu ilişkilerin niteliği, ilişki içinde bireyin kendine ilişkin almış olduğu geribildirimler günlük yaşam üzerinde etkili olmaktadır. İnsan ilişkilerinde bireyin karşısındakini anlama potansiyeli olarak tanımlanabilecek olan empati, ilişkilerin niteliğini belirleme açısından önemli bir özellik olarak görülmektedir (Hortaçsu, 2003; Kaya ve Siyez, 2010; Köksal Akyol vd., 2011a; Yılmaz Yüksel, 2003;).

Feshbach, (1987), Lawrence vd. (2004), Gini, vd. (2007), empatinin farklı boyutlarının olduğu üzerinde durmaktadırlar. Empatinin bilişsel ve duygusal öğelerden oluştuğunu ve duruma göre bilişsel ya da duygusal boyutta tepki verilebildiğini kabul edilmektedir (Brems, 1989; Eisenberg ve Strayer 1987). Diğer kişinin bakış açısını değerlendirebilme anlamına gelen empatinin bilişsel boyutu bireylerin sosyal işlevselliğinde etkili olmaktadır (Smith, 2006). Empatinin duygusal boyutu, diğer kişinin yaşadığı duyguyu hissedebilme ve diğerinin duygusal durumuna en uygun tepkiyi verebilme anlamına gelmektedir (De Kemp vd. 2007; De Wied vd. 2005). Cohen ve Strayer (1996) empati kavramını, genellikle karşıdaki kişinin duygusal durumunun anlaşılması ve paylaşılması olarak tanımlamaktadırlar. Günümüzde empatinin en çok kabul gören tanımlarından biri Rogers 
tarafından yapılmıştır. Rogers'a göre, empati; "bir kişinin kendisini karşısındaki kişinin yerine koyarak olaylara onun bakış açısı ile bakması, o kişinin duygularını ve düşüncelerini doğru olarak anlaması, hissetmesi ve bu durumu ona iletmesi" sürecidir (Dökmen, 1988).

Ergenlik döneminde aile, arkadaş ve diğerleri ile ilişkiler farklılaşmakta, ailenin yanı sıra arkadaşlar ve öğretmenler de önemli destek kaynakları arasında yer almakta, bu kişilerle kurulan olumlu ve olumsuz ilişkilerden etkilenmeler oldukça kolay olabilmektedir. Bu nedenle bu dönemdeki çocukların empatik eğilime sahip olmaları ve bu becerilerini sorunlarını çözmede kullanmaları oldukça önemlidir. Empatik becerisi yüksek olan çocuk kendisini karşısındakinin yerine koyarak olaylara daha farklı yaklaşabilmekte ve iletişim sorunlarını sağlıklı bir şekilde çözümleyebilmektedir. İnanç vd. (2005)'e göre, empatik becerisi düşük olan ergenin arkadaşlarını ve ailesini anlamada güçlüklerle karşılaşması çoğu kez kaçınılmazdır. Bu da ergenin çevresi tarafından dışlanmasına yol açabilmektedir. Aile bilgi, değer, tutum, rol ve alışkanlıkların kuşaktan kuşağa aktarılmasında en önemli rolü üstlenir (İnanç vd., 2005; Yavuzer, 1984).

Literatür incelendiğinde, anne-babaların empatik becerileri ile çocukların bakış açısı alma becerileri (Oğuz ve Köksal Akyol, 2008), annelerin empatik becerileri ile çocukların öz saygı düzeyleri (Körükçü, 2004) anne-baba tutumları ve annelerin kabul-red düzeyleri ile çocuklarının empatik becerileri (Çetin, 2008; Önder ve Gülay, 2007) arasındaki ilişkinin incelendiği araştırmaların olduğu görülmektedir. $\mathrm{Bu}$ araştırmalarda, anne-babaların empatik becerilerinin çocukları üzerindeki etkileri ile anne-babaların çocuk yetiştirme tutumlarının çocukların empatik becerilerindeki etkilerinin ortaya konulmuştur. Ancak anne babaların empatik becerilerinin çocuklarının empatik becerileri üzerindeki etkilerini ortaya koymaya yönelik çalışmaların olmadığı dikkati çekmektedir. Ayrıca, empatik anne-babaların da çocukları anne babalarını model alarak ilişkilerinde empatik beceriyi kullanabildikleri kabul edilmektedir. Bu nedenlerden dolayı, araştırmada, ergenler ile anne-babalarının empatik becerilerinin belirlemesi ve elde edilen bulgular doğrultusunda bazı önerilerde bulunulması amaçlanmıştır. 


\section{YÖNTEM}

\section{Araştırmanın Modeli}

Bu araştırma, ergenler ile anne-babalarının empatik becerilerinin incelenmesi, ergenin cinsiyetinin ergenlerin ve anne-babalarının empatik becerilerinde farklılığa neden olup olmadığının belirlenmesi amacıyla yapılan betimsel bir çalışmadır.

\section{Çalışma Grubu}

Araştırmanın çalışma grubunda Ankara il merkezinde bulunan Milli Eğitim Bakanlığına bağlı lise ikinci sınıfta öğrenimini sürdüren 300 ergen ile bu ergenlerin anne $(n=300)$ ve babaları $(n=300)$ olmak üzere 900 kişi bulunmaktadır.

\section{Veri Toplama Araçları}

Araştırmada veri toplama aracı olarak, Demografik Bilgi Formu ile Dökmen tarafından (1988, 1990) Empatik Beceri Ölçeği B Formu (EBÖ-B Formu) kullanılmıştır.

Demografik Bilgi Formu: Ergenler ve anne-babaları hakkında bilgi toplamak amacıyla araştırmacılar tarafından düzenlenmiştir.

Empatik Beceri Ölçeği B Formu (EBÖ-B Formu): Araştırmada empatik beceriyi ölçmek amacıyla kullanılan Empatik Beceri Ölçeği-B Formu (EBÖ-B formu) Dökmen'in aşamalı sınıflamasına dayanılarak geliştirilmiş olup, empatinin bilişsel bileşenine ağırlık veren bir ölçme aracıdır. EBÖ-B Formu, güvenirliğinin ve geçerliğinin incelenmesi amacıyla, Ankara Üniversitesi Eğitim Bilimleri Fakültesi birinci sınıf öğrencilerinden 60 kişiye ve çeşitli kurumlarda çalışan 24 psikoloğa uygulanmıştır. Güvenirlik çalışması için EBÖ-B Formu, 60 deneğe iki hafta arayla uygulanmış ve $r=.83 \quad(P<.001)$ bulunmuştur. Geçerlik çalışmasında, öğrenciler ile psikologlar arasında psikologlar lehine anlamlı bir fark olduğu görülmüştür. $(t=8.15, p<.001)$. Diğer bir geçerlik çalışmasında da EBÖ-B Formu ile Rol Alma Testi (RAT) arasında $r=.78(p<.001)$ düzeyinde ilişki bulunmuştur (Dökmen, 1988, 1990).

Ölçek, günlük yaşamla ilgili kısa ifadelerin bulunduğu altı ayrı psikolojik sorundan oluşmaktadır. Bireylere yöneltilen bu sorunlara ilişkin verilebilecek on iki tepki bulunmaktadır. Bireylerden, bu on iki tepkiden dördünü seçmeleri istenmektedir. Bireyin seçtiği tepkilere puanlama anahtarındaki puanlar verilmektedir. Bu puanların toplamı, deneğin EBÖ-B Formu'ndan aldığı toplam puanı göstermektedir. Her 
sorunun altında verilen on iki tepkiden biri anlamsızdır ve bu maddeyi seçen bireyin formu geçersiz sayılmaktadır (Dökmen, 1988, 1990).

\section{Verilerin Analizi}

Araştırmada ergenlerden ve anne-babalarından elde edilen veriler puanlanmış ve SPSS 11,5 kullanılarak analiz edilmiştir. Verilerin analizinde ANOVA kullanılmıştır. ANOVA sonuçlarının anlamlı çıkması durumunda farkların hangi gruptan kaynaklandığını bulmak için Tukey çoklu karşılaştırma testi uygulanmıştır (Büyüköztürk, 2002).

\section{BULGULAR VE TARTIŞMA}

Ergenler ile anne-babalarının empatik becerilerinin incelenmesi, ergenin cinsiyetinin ergenlerin ve anne-babalarının empatik becerilerinde farklılığa neden olup olmadığının belirlenmesi amacıyla yapılan bu araştırmanın bulguları aşağıda sunulmuştur.

Tablo 1. Ergenin Cinsiyetine Göre Ergenler ile Anne ve Babalarının Empatik Beceri Puanlarına İlişkin Ortalamalar, Standart Sapmalar ve ANOVA Sonuçları

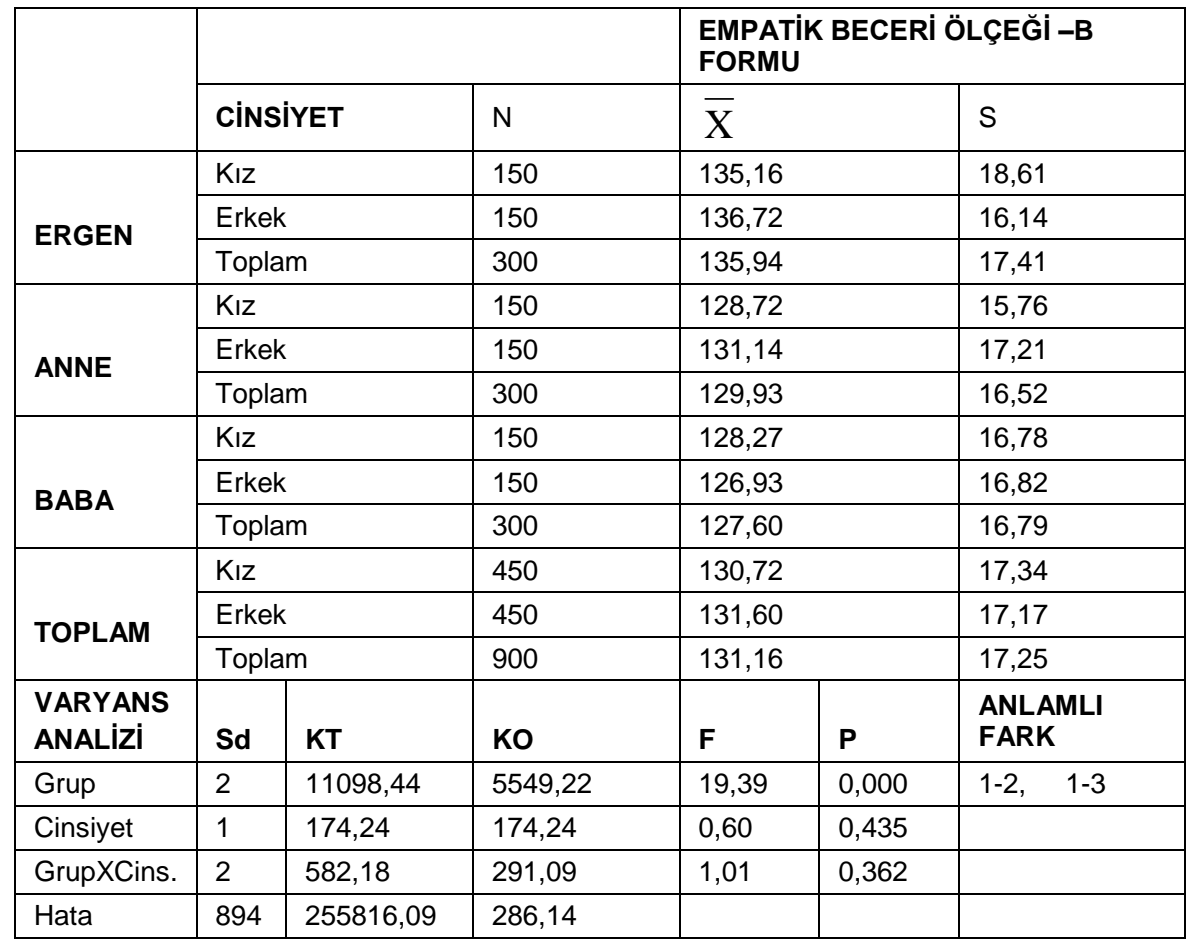


Tablo 1'de; ergenin cinsiyetine göre ergenler ile anne ve babalarının empatik becerilerine ilişkin puan ortalamaları, standart sapmalar, iki faktörlü varyans analizi (ANOVA) ve Tukey testi sonuçları görülmektedir. Ergenlerin empatik becerilerinin ( $\bar{X}=135.94)$, annelerin $(\bar{X}=129.93)$ ve babaların $(\bar{X}=127.60)$ empatik becerilerinden daha yüksek olduğu saptanmıştır. Yapılan ANOVA sonucunda, ergenler ile anne ve babaların empatik beceri puanları arasında anlamlı bir farkın olduğu bulunmuştur $[F(2,894)=$ 19.39, p<.01]. Yapılan Tukey testi sonucunda, ergenlerin empatik becerileri ile annelerin ve babaların empatik becerileri arasında farklılığın anlamlı düzeyde olduğu belirlenmiştir. Ergenin cinsiyetine göre ergenler ile anne ve babalarının empatik becerilerine ilişkin ANOVA sonuçları incelendiğinde ise, ergenin cinsiyetinin ergenler ile anne ve babaların empatik beceri puanları üzerinde anlamlı bir farklılığa neden olmadığı görülmektedir $[F(1.894)=0.60, p>.05]$.

Araştırma sonucunda, ergenlerin empatik becerilerinin anne ve babalarının empatik becerilerinden daha yüksek olduğu bulunmuştur. Kalliopuska ve Titinen (1991)'e göre, ebeveynlerin empatik becerileri çocukların empatik becerilerin gelişimi üzerinde etkili olmaktadır. Feshbach, (1990) empatik becerisi düşük olan ebevenlerin çocuklarının da empatik becerilerinin düşük olduğunu vurgulamıştır. Köksal (2000a)'a göre, çocukların diğer insanların duygusal durumlarına karşı gösterdikleri tepkilerde bireysel farklılıklar vardır ve bireysel farklılıklarda çocukların kendilerine model aldıkları anne, baba ve yakın çevredeki diğer bireylerin etkisi olabilmektedir. Ancak yapılan bazı araştırmalarda, çocukların empatik becerileri ya da bakış açıları ile anne-babalarının empatik becerileri arasında bir ilişkinin olmadığı belirlenmiştir. Oğuz ve Köksal Akyol (2008) anne-babaların empatik becerileri ile çocukların bakış açısı alma becerileri arasındaki ilişkiyi incelemek üzere yaptıkları araştırmada, anne-babaların empatik becerilerinin çocukların bakış açısı alma becerilerinde etkili olmadığını belirlemişlerdir. Kalliopuska (1984), çocuklar ile annebabalarının empatik becerilerini incelediği araştırmanın sonucunda, çocuklar ile anne-babaların empatik becerileri arasında herhangi bir farklıı̆ın olmadığı sonucuna ulaşmıştır. Garner vd (1997) annenin empatik becerisi ile çocukların duygusal bakış açısı almaları arasında bir ilişkinin olmadığını yaptıkları bir araştırmada ortaya koymuşlardır. Ergenler ile anne-babaların empatik becerilerinin incelendiği bu araştırmada ise, anne-babalar arasında empatik beceri açısından bir farklılığın olmadığı, ancak ergenlerin empatik becerilerinin her iki ebeveyninden daha yüksek olduğu saptanmıştır. Gelişime daha açık 
olan ergenlerin empatik becerilerinin gelişmesine aile dışında farklı faktörlerin etki etmiş olabileceği söylenebilir. Günümüzde, empati kavramı üzerinde günlük yaşamdan eğitim seminerlerine kadar bir çok alanda sıklıkla durulmaktadır. Ergenlerin devam ettikleri okullarda çalışan eğitimcilerin de geçmiş dönemlere göre daha çok etkili iletişim becerileri üzerinde durdukları gözlemlenmektedir. Bu nedenlerden dolayı ergenlerin empatik becerileri anne-babalarından daha yüksek çıkmış olabilir.

Ergenin cinsiyetinin; ergenler ile anne ve babalarının empati becerileri üzerinde herhangi bir etkisinin olmadığı bulunmuştur. Empatik beceri üzerine yapılan araştırmalarda, cinsiyetin etkisine yönelik farklı sonuçların belirlendiği dikkati çekmektedir; Cinsiyetin empatik beceri üzerinde farklılığa yol açtığını, kızların erkeklere oranla daha empatik olduğunu belirleyen çalışmaların yanı sıra, bu araştırmada elde edilen bulguya paralel olarak cinsiyetin empatik beceri üzerinde herhangi bir etkisinin olmadığını ortaya koyan araştırmaların olduğu görülmektedir. Bryant (1982), Eisenberg ve Lennon (1983), Hietolahti-Ansten ve Kalliopuska (1990), Kalliopuska (1991), Köksal (2000b), Alver (1998), Öner (2001), Akın (2002), (Köksal, 1997). Ulutaş (2005), Köksal Akyol ve Oğuz (2007) ile Köksal Akyol vd. (2011b) tarafından yapılan çalışmalarda da, cinsiyetin çocukların bakış açısı alma becerisi ve empatik becerilerinde herhangi bir farklılığa neden olmadığını belirlenmiştir. Bu veriler, yapılan bu araştırma sonuçları ile paralellik göstermektedir.

\section{SONUÇ}

Ergenler ile anne-babalarının empatik becerilerinin incelenmesi, ergenin cinsiyetinin ergenlerin ve anne-babalarının empatik becerileri üzerinde farklıı̆̆a neden olup olmadığının belirlenmesi amacıyla yapılan bu araştırmada, ergenlerin anne ve babalarından daha yüksek bir empatik beceri düzeyine sahip oldukları ve ergenin cinsiyetinin ergenler ile anne-babalarının empatik becerilerinde farklıı̆ga neden olmadığı belirlenmiştir.

Araştırmada elde edilen bulgular doğrultusunda aşağıda bazı önerilere yer verilmiştir;

- Ergenlerin empatik becerilerinin anne-babalardan daha yüksek olduğu belirlenmiştir. Anne-babaların empatik becerilerinin de yüksek olması aile ortamlarında daha olumlu bir iletişim ortamının oluşmasına katkıda bulunacaktır. Bu nedenle, anne- 
babaların empatik becerilerinin geliştirilmesine yönelik eğitim programları düzenlenebilir.

- Aile dışında okul ortamında da uzun zaman dilimlerini geçiren ergenlerin eğitiminde rol alan öğretmenlerin empatik becerilerini geliştirmeye yönelik çalışmalar yapılabilir. Böylece, hem empatik bir iletişimin olduğu bir eğitim ortamı sağlanmış hem de yüksek empatik becerileri olan öğretmenler iyi birer model olacakları için ergenlerin de empatik becerileri gelişmiş olacaktır.

- Bundan sonra yapılacak çalışmalarda, ergenler ile annebabalarına empati eğitim programının uygulanacağı deneysel desenli araştırmalar yapılabilir.

- Ergenler ile anne-babalarının empatik becerileri ile birlikte benlik kavramları, denetim odakları gibi bazı kişilik özellikleri arasındaki ilişkinin incelendiği araştırmalar planlanabilir. 


\section{KAYNAKLAR}

Akın, Y. (2002) Altı yaş grubu çocuklarında başkasının bakış açısını alma yetisi üzerinde eğitici drama programının ve aile tutumlarının etkisinin incelenmesi. Yüksek Lisans Tezi (Basılmamış), Marmara Üniversitesi, Sosyal Bilimler Enstitüsü, İstanbul.

Alver, B. (1998). Bireylerin uyum düzeyleri ile empatik becerileri arasındaki ilişkiler, Yüksek Lisans Tezi (Basılmamış), Atatürk Üniversitesi, Sosyal Bilimler Enstitüsü, Erzurum.

Brems, C. (1989). Dimensionality of empathy and its correlates. Journal of Psychology, 123(4), 329-337.

Bryant, T. (1982). An index of empathy for children and adolesents. Child Devolopment, 53, 413-425.

Büyüköztürk, Ş. (2002). Sosyal bilimler için veri analizi el kitabı istatistik, araştırma deseni SPSS uygulamaları ve yorum. Pegem A Yayıncılık, Ankara.

Cohen, D. and Strayer, J. (1996). Empathy in conduct disordered youth. Developmental Psychology, 32,988-998.

Çetin, C.N. (2008). İlköğretim dördüncü sınıf öğrencilerinin empatik beceri düzeylerinin ana baba tutumları ve özsaygı ile ilişkisi. Yüksek Lisans Tezi. (Basılmamış), Gazi Üniversitesi, Sosyal Bilimler Enstitüsü, Ankara.

De Kemp, R.A.T., Overbeek, G., De Wied, M., Engels, R.C.M.E. and Scholte, R.H.J. (2007). Early adolescent empathy, parental support, and antisocial behavior. The Journal of Genetic PSychology, 168 (1), 5-18.

De Wied, M., Goudena, P.P. and Matthys, W. (2005). Empathy in boys with disruptive behvaior disorders. Journal of Child Psychology and Psychiatry, 46(8), 867-880.

Dökmen, Ü. (1988). Empatinin yeni bir modele dayanarak ölçülmesi ve psikodrama ile geliştirilmesi. Ankara Üniversitesi Eğitim Bilimleri Fakültesi Dergisi, 21 (1-2), 155-190.

Dökmen, Ü. (1990). Yeni bir empati modeli ve empatik becerilerin iki farklı yaklaşımla ölçülmesi. Psikoloji Dergisi, 7(24), 45-50.

Dökmen, Ü. (1994). İletişim çatışmaları ve empati. Sistem Yayıncılık, İstanbul. 
Eisenberg, N. and Lenon, R. (1983). Sex differences in empathy and related capacities. Psychological Bulletin, 94 (1), 100-131.

Eisenberg, N. and Stayer, J. (1987). Empathy and its development. Cambridge University Press, New York.

Feshbach, N.D. (1987). Parental empathy and child adjusment/maladjusment. Empathy And Its Development, (Ed: N.Eisenberg and J. Strayer ), Cambricge: Cambridge University Press, p. 271-292, New York.

Feshbach, N. D. (1990). Parental empathy and child adjustment maladjustment. Empathy and Its Development, (Ed: Eisenberg, N. and Strayer, J). Cambridge University Press, p. 271-292, Cambridge.

Garner, P.W., Carlson Jones, D. and Rennie, K.M. (1997) Low income mothers' conversations about emotions and their chidren's emotional competence. Social Development, 6(1), 3752.

Gini, G., Albiero, P., Benelli, B. and Altoe, G. (2007). Does empathy predict adolescents' bullying and defending behavior? Aggressive Behavior, 33(5); 467-476.

Hietolahti-Ansten, M. and Kalliopuska, M. (1990). Self-esteem and empathy among children actively involved in music, Perceptual and Motor Skills, 71(3), 1364-1366.

İnanç, B.Y., Bilgin, M. ve Kılıç Atıcı, M. (2005). Gelişim psikolojisi çocuk ve ergen gelişimi. Nobel Kitabevi, Adana.

Kalliopuska, M. (1984). Relation between children's and parent's empathy. Psychological Reports, 5, 295-299.

Kalliopuska, M. (1991). Empathy among children in music. Perceptual anda Motor Skills, 72, 383-386.

Kalliopuska, M. (1992). Holistic empathy education among preschool and school children. Paper Present at the International Scientific Conference Comenius Heritage and Education of Man. March 23-27, (p. 1-20), Praque.

Kalliopuska, M. and Titinen, U. (1991) Influence of two developmental programmes on the empathy and prosociability of pre-school children. Perceptual and Motor Skills, 72, 323-328. 
Kaya, A. ve Siyez D.M. (2010). KA-SI çocuk ve ergenler için empatik eğilim ölçeği: geliştirilmesi geçerlik ve güvenirlik çalışması. Eğitim ve Bilim, 25(156), 110-125.

Köksal Akyol, A., Akıncı, E. and Yıldız Bıçakçı, M. (2011 b). Study on emphatic skill levels of fourth grade students attending elemantary school. The 2011 Barcelena European Acedemic Conference. Conference Proceedings, ISSN Number: 1539-8757 (print); 2157-9660 (online). p. 877-884. Barcelona, Spain.

Köksal Akyol, A., Sali, G. and Körükçü, Ö. (2011 a). Children's emphatic tendencies with respect to their gender and grade level. The 2011 Barcelena European Acedemic Conference. Conference Proceedings, ISSN Number: 1539-8757 (print); 2157-9660 (online). p. 1045-1051. Barcelona, Spain.

Köksal, A. (2000a). Çocuklarda empatinin gelişmesi. Yaşadıkça Eğitim, 66, 1-7.

Köksal, A. (2000b). Müzik eğitimi alma, cinsiyet ve sınıf düzeyi değişkenlerine göre ergenlerin empatik becerilerine ve uyum düzeylerinin incelenmesi. Hacettepe Üniversitesi Eğitim Fakültesi Dergisi, 18, 99-107.

Köksal, A. and Oğuz, V. (2007). An investigation into the perspective taking skills of 6 year old children in terms of pet feeding and gender variables. Humanity and Social Sciences Journal, 1(1), 96-100.

Körükçü, Ö.S. (2004). Altı yaş grubundaki çocukların öz saygı düzeyleri ile anne empatik becerilerinin incelenmesi. Doktora tezi (Basılmamış), Ankara Üniversitesi Fen Bilimleri Enstitüsü, Ankara.

Lawrence, E.J., Shaw, P., Baker, D., Baron-Cohen, S. and David, A.S. (2004). Measuring empathy: reliability and validity of the empathy quotient. Psychological Medicine, 34, 911-924.

Oğuz, V. and Köksal Akyol, A. (2008). Perspective- taking skills of 6year-old children: preschool attendance and mothers' and fathers' education and empathetic skills. Perceptual and Motor Skills, 107, 481-493.

Önder, A., ve Gülay, H. (2007). Annelerin kabul red düzeyi ile çocuklarının empati becerisi arasındaki ilişkinin incelenmesi. Pamukkale Üniversitesi Eğitim Fakültesi Dergisi, 22(2), 23-30. 
Öner, N. (2001). Farklı cinsiyet rol yönelimli kız ve erkek üniversite öğrencilerinin empatik beceri düzeylerinin karşılaştırılması. Yüksek Lisans Tezi (Basılmamış), Ankara Üniversitesi, Sosyal Bilimler Enstitüsü, Ankara.

Smith A. (2006). Cognitive empathy and emotional empathy in human behavior and evaluation. The Psychological Record, 56, 3-21.

Ulutaş, ì. (2005) Anasınıfına devam eden altı yaş çocuklarının duygusal zekalarına duygusal zeka eğitiminin etkisinin incelenmesi. Doktora tezi (Basılmamış), Gazi Üniversitesi, Eğitim Bilimleri Enstitüsü, Ankara.

Woolfolk, A. E. (1993). Educational psychology. Fifth Edition, Simon and Schuster Inc., London.

Yavuzer, H. (1984). Ergenlik dönemi özellikleri ve sorunları, aile ve çocuk konferansları. Ak Yayınları, İstanbul.

Yılmaz Yüksel, A. (2003). Empati eğitim programının ilköğretim öğrencilerinin empatik becerilerine etkisi. Doktora Tezi (Basılmamış), Ankara Üniversitesi Eğitim Bilimleri Enstitüsü, Ankara.

Yüksel, A. (2004). Empati eğitim programının ilköğretim öğrencilerinin empatik becerilerine etkisi. Uludağ Üniversitesi Eğitim Fakültesi Dergisi, 17(2), 341-354. 